\title{
Summary Abstract: Kinetics and mechanism of formic acid decomposition on $\mathrm{Ru}(001)$
}

\author{
Y.-K. Sun, J.J. Vajo, ${ }^{\text {a) }}$ C.-Y. Chan, and W. H. Weinberg \\ Division of Chemistry and Chemical Engineering, California Institute of Technology, Pasadena, \\ California 91125
}

(Received 7 December 1987; accepted 13 January 1988)

The steady-state rate of decomposition of formic acid on $\mathrm{Ru}(001)$ has been measured as a function of surface temperature, parametric in the pressure of formic acid. The products of the decomposition reaction are $\mathrm{CO}_{2}, \mathrm{H}_{2}, \mathrm{CO}$, and $\mathrm{H}_{2} \mathrm{O}$, i.e., both dehydrogenation and dehydration occur on $\mathrm{Ru}(001)$. A similar product distribution has been observed on $\mathrm{Ni}(110),{ }^{1} \mathrm{Ni}(100),{ }^{2} \mathrm{Ru}(100),{ }^{3} \mathrm{Fe}(100),{ }^{4}$ and $\mathrm{Ni}(111)^{5}$ surfaces; whereas only dehydrogenation to $\mathrm{CO}_{2}$ and $\mathrm{H}_{2}$ occurs on the $\mathrm{Cu}(100),{ }^{6} \mathrm{Cu}(110),{ }^{7}$ and $\mathrm{Pt}(111)^{8}$ surfaces. Only reversible adsorption and desorption of formic acid is observed on the less reactive $\mathrm{Ag}(110)$ surface at low temperatures, ${ }^{4}$ whereas the more reactive $\operatorname{Mo}(100)$ surface is oxidized by formic acid at low temperatures with the products of this reaction being $\mathrm{H}_{2}, \mathrm{CO}$, and $\mathrm{H}_{2} \mathrm{O}$ (Ref. 10 ). We report here the confirmation of earlier observations of the occurrence of both dehydrogenation and dehydration of formic acid on $\mathrm{Ru}(001),^{11,12}$ and more importantly, we provide a detailed mechanistic description of the steady-state decomposition reaction on this surface in terms of elementary steps.

Details concerning both the UHV system that was employed in this work ${ }^{13}$ as well as crystal preparation and cleaning ${ }^{14}$ have been presented previously. The formic acid was introduced onto the $\mathrm{Ru}(001)$ surface through a directional beam doser consisting of a multichannel array of capillaries, and the ratio of the "beam pressure" of formic acid at the surface when the crystal was in front of the doser to the background pressure of formic acid in the UHV chamber was $>40$. Under our experimental conditions, the incident formic acid was predominantly in monomer form. The rate of decomposition of the formic acid was measured by a multiplexed quadrupole mass spectrometer (UTI-100C) as the $\mathrm{Ru}(001)$ surface was positioned in and out of the formic acid beam with the surface temperature held constant. The measurements were carried out at surface temperatures between 350 and $800 \mathrm{~K}$ and for formic acid pressures of $7.3 \times 10^{-7}$ and $2.1 \times 10^{-6}$ Torr.

Arrhenius plots of the rate of decomposition of formic acid on $\mathrm{Ru}(001)$ are shown in Fig. 1 from which it is clear that there are two quite distinct kinetic regimes, labeled I and $I I$ in the figure. At relatively low surface temperatures between 360 and $400 \mathrm{~K}$ (regime II), the reaction rate is zero order in formic acid pressure with apparent activation energies of $16.0 \pm 0.3 \mathrm{kcal} / \mathrm{mol}$ for $\mathrm{CO}_{2}$ and $\mathrm{H}_{2}$ production, and $15.0+1.0 \mathrm{kcal} / \mathrm{mol}$ for $\mathrm{CO}$ and $\mathrm{H}_{2} \mathrm{O}$ production. At temperatures above $500 \mathrm{~K}$ (regime I) the reaction rate becomes first order in formic acid pressure with apparent activation energies of $-1.3+0.2 \mathrm{kcal} / \mathrm{mol}$ for $\mathrm{CO}_{2}$ and $\mathrm{H}_{2}$ production, and $-0.2 \pm 0.3 \mathrm{kcal} / \mathrm{mol}$ for $\mathrm{CO}$ and $\mathrm{H}_{2} \mathrm{O}$ produc- tion. The logarithm of the ratio of the rate of production of $\mathrm{CO}_{2}$ and $\mathrm{H}_{2}\left(=\mathrm{R}_{\mathrm{CO}_{2}}\right)$ to that of $\mathrm{CO}$ and $\mathrm{H}_{2} \mathrm{O}\left(\equiv \mathrm{R}_{\mathrm{CO}}\right)$ is plotted as a function of reciprocal surface temperature in Fig. 1(b). It is apparent that the rate of dehydrogenation is two to three times greater than that of dehydration in regime II, and five to eight times greater in regime $I$.

The kinetics of dehydrogenation of $\mathrm{DCOOH}$ were measured and compared with those of $\mathrm{HCOOH}$. They are essentially the same in regime I. At relatively low temperatures (regime II), however, the apparent activation energy for $\mathrm{DCOOH}$ is $17.1 \pm 0.3 \mathrm{kcal} / \mathrm{mol}$, compared to $16.0 \pm 0.3$ $\mathrm{kcal} / \mathrm{mol}$ for $\mathrm{HCOOH}$. The absolute rate of dehydrogenation of $\mathrm{HCOOH}$ in regime II is greater than that of DCOOH.
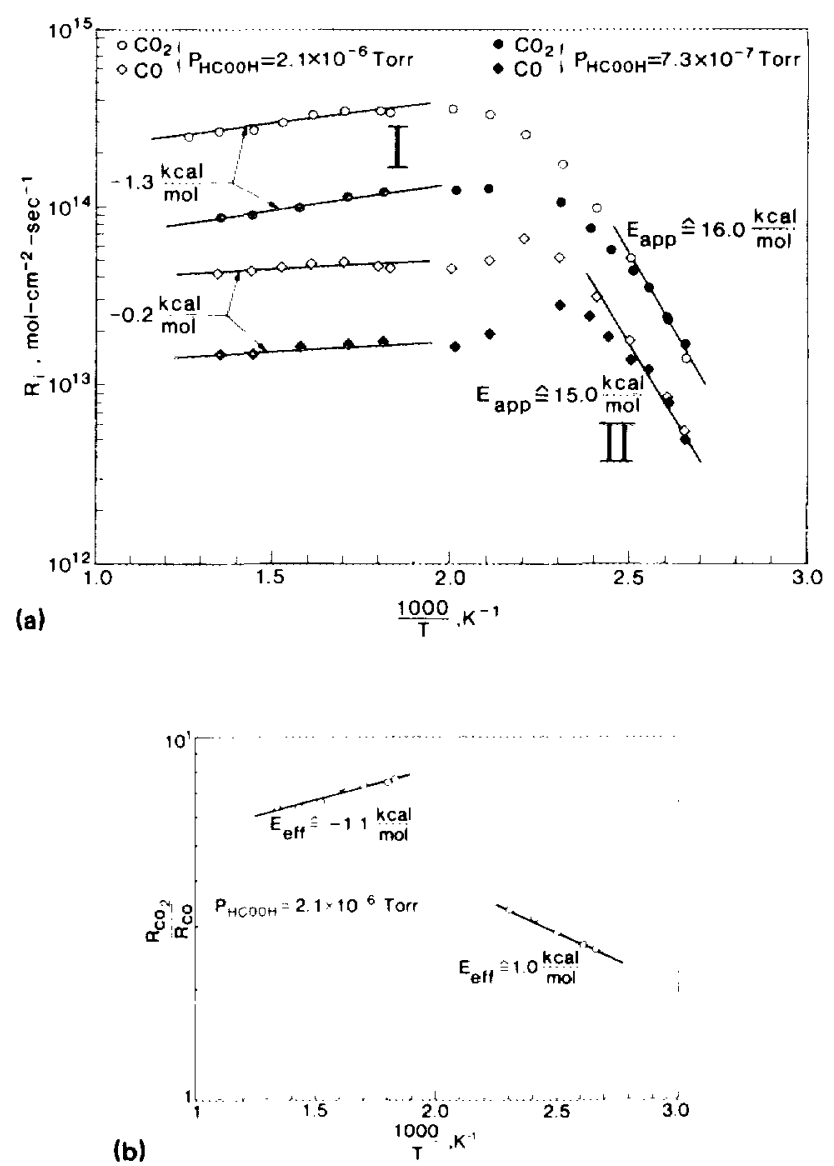

FIG. 1. (a) Arrhenius plots of the steady-state rate of decomposition of formic acid on $\mathrm{Ru}(001)$. Note that the reaction is zero order below $\sim 400 \mathrm{~K}$ and first order above $500 \mathrm{~K}$. (b) Logarithm of $R_{\mathrm{CO}} / R_{\mathrm{CO}}$ as a function of reciprocal temperature. 
This difference in the kinetics of dehydrogenation of $\mathrm{DCOOH}$ and $\mathrm{HCOOH}$ is due to a kinetic isotope effect, and indicates that $\mathrm{C}-\mathrm{H}$ bond cleavage is involved in the ratelimiting step under these conditions. A third kinetic regime (regime III, not shown in Fig. 1) was observed below $370 \mathrm{~K}$ for the dehydrogenation of $\mathrm{DCOOH}$. The rate is zero order in formic acid pressure in regime III with an apparent activation energy of $29.0 \pm 0.6 \mathrm{kcal} / \mathrm{mol}$.

A bidentate formate species has been identified by electron energy-loss spectroscopy to be the stable intermediate upon adsorption of formic acid on $\mathrm{Ru}(001)$ at $90 \mathrm{~K}$ with subsequent annealing to between 200 and $375 \mathrm{~K} . .^{11,12}$ Chemisorbed carbon monoxide and oxygen adatoms were observed spectroscopically on the surface after annealing to higher temperatures. The observation of the isotope effect for $\mathrm{C}-\mathrm{H}$ bond cleavage together with the fact that formate is a stable intermediate clearly indicate that formate decomposition is the rate-limiting step in kinetic regime II.

Additional insight into the reaction mechanism can be gained if one has knowledge of the coverages of the various surface species during the steady-state reaction. Transient thermal desorption measurements carried out during the steady-state reaction ${ }^{15}$ allow the determination of DCOO, $\mathrm{D}, \mathrm{H}$, and $\mathrm{CO}$ coverages during the steady-state decomposition of DCOOH. For pressures of DCOOH near $10^{-6}$ Torr, the hydrogen coverage is much smaller than that of deuterium in kinetic regimes II and III. Furthermore, the thermal desorption spectra of $\mathrm{D}_{2}$ and $\mathrm{CO}_{2}$ from $\mathrm{DCOOH}$ adsorbed at $300 \mathrm{~K}$ have the same shape and peak temperature. These facts imply that the formation of $\mathrm{D}_{2}$ and $\mathrm{CO}_{2}$ are governed by the same rate-limiting step, the decomposition of surface formate. The evolution of $D_{2}$ is reaction limited, whereas that of $\mathrm{H}_{2}$ is desorption limited. The formate coverage (and thus the D coverage) remains essentially constant in kinetic regime III and decreases with increasing temperature in regime II with an activation energy given by $k_{B} d\left(\ln \theta_{\text {Dcoo }}\right) /$ $d\left(T^{-1}\right)=-13.3 \pm 1.0 \mathrm{kcal} / \mathrm{mol}\left(\equiv E_{\theta_{\mathrm{DCOO}}}\right)$. The activation energy $E$ for the elementary reaction $\operatorname{DCOO(a)}$ $\rightarrow \mathrm{CO}_{2}(\mathrm{~g})+\mathrm{D}(\mathrm{a})$, the apparent activation energy of dehydrogenation $E_{\text {app }}$, and $E_{\theta_{\mathrm{DCOO}}}$ are related by $E_{\mathrm{app}}=E-E_{\theta_{\mathrm{DCC} O}}$. Since $E_{\theta_{\mathrm{DCOO}}} \simeq 0$ in regime III, the apparent activation energy measured in this regime is the reaction barrier for formate to decompose via $\mathrm{C}-\mathrm{D}$ bond cleavage ( $\left.E=E_{\text {app }}=29.0 \pm 0.6 \mathrm{kcal} / \mathrm{mol}\right)$. Utilizing the value $E_{\text {app }}=17.1 \pm 0.3 \mathrm{kcal} / \mathrm{mol}$ from regime II yields $E=30.4 \pm 1.3 \mathrm{kcal} / \mathrm{mol}$, which agrees well with the value obtained from regime III $(29.0 \pm 0.6 \mathrm{kcal} / \mathrm{mol})$. These results together with the kinetic isotope effect observed in regime II imply that the rate in regime III is also limited by the decomposition of formate.

The fact that the dissociative chemisorption of formic acid is irreversible was confirmed by reacting a mixture of $\mathrm{HCOOH}$ and $\mathrm{D}_{2}$ of which the molar ratio was $1: 2$ and observing no mass 47 (HCOOD) as a reaction product under any conditions. The important fact that a secondary reaction leading to $\mathrm{CO}_{2}$ via the oxidation of $\mathrm{CO}$ does not occur was established by carrying out the decomposition reaction at $500 \mathrm{~K}$ on a $\mathrm{Ru}(001)$ surface on which a half-monolayer of
${ }^{18} \mathrm{O}$ was predosed. The only initially observed reaction products were $\mathrm{H}_{2}, \mathrm{C}^{16} \mathrm{O}^{16} \mathrm{O}$, and $\mathrm{H}_{2}^{18} \mathrm{O}$. As the ${ }^{18} \mathrm{O}$ was depleted from the surface, $\mathrm{C}^{16} \mathrm{O}$ was also observed as a reaction product; in no case was $\mathrm{C}^{16} \mathrm{O}^{18} \mathrm{O}$ detected, ruling out the secondary oxidation of $\mathrm{CO}$ on $\mathrm{Ru}(001)$ during the steady-state decomposition of formic acid.

The transition region seperating kinetic regimes I and II occurs between approximately 425 and $475 \mathrm{~K}$, and it is characterized both by the desorption of chemisorbed $\mathrm{CO}$ from $\mathrm{Ru}(001)$ and by the accumulation of oxygen adatoms on the surface. Auger electron spectroscopic data revealed that the concentration of oxygen adatoms is negligible below $425 \mathrm{~K}$ during the steady-state reaction, and approaches a quartermonolayer as the temperature increases above $475 \mathrm{~K}$. The presence of oxygen leads to an enhancement in the rate of production of $\mathrm{CO}_{2}$ relative to $\mathrm{CO}$.

To summarize, for formic acid pressures near $10^{-6}$ Torr, there are three distinct kinetic regimes in the steady-state decomposition reaction on $\mathrm{Ru}(001)$ : regime I above $500 \mathrm{~K}$, regime II between 360 and $400 \mathrm{~K}$, and regime III below 370 K. At relatively low surface temperatures (regimes II and III) the rate is limited by the decomposition of surface formate; whereas at high temperatures, the rate is limited by the formation of formate from molecularly adsorbed formic acid. The low-temperature regimes are characterized by a $\mathrm{Ru}(001)$ surface that is essentially saturated with reaction intermediates. The coverage of $\mathrm{CO}$ remains approximately constant in regimes II and III and decreases above $425 \mathrm{~K}$. The formate coverage is relatively constant in regime III and decreases rapidly in regime II. The surface hydrogen coverage is insignificant compared to those of $\mathrm{CO}$ and formate. The high-temperature regime is characterized by a surface on which there is a steady-state concentration of oxygen adatoms approaching a quarter-monolayer. The latter selectively enhances the rate of dehydrogenation $\left(\mathrm{CO}_{2}\right.$ and $\mathrm{H}_{2}$ production) relative to dehydration ( $\mathrm{CO}$ and $\mathrm{H}_{2} \mathrm{O}$ production). A detailed account of this work, including mechanistic modeling, will be presented elsewhere. ${ }^{16}$

Acknowledgment: This work was supported by the National Science Foundation under Grant No. DMR-8500789.

") Present address: SRI International, Menlo Park, CA 94025.

'J. L. Falconer and R. J. Madix, J. Catal. 31, 47 (1978)

${ }^{2}$ J. B. Benziger and R. J. Madix, Surf. Sci. 79, 394 ( 1979).

${ }^{3}$ L. A. Larson and J. T. Dickenson, Surf. Sci. 84, 17 (1979)

J. B. Benziger and R. J. Madix, J. Catal. 65, 49 ( 1980)

${ }^{5}$ J. B. Benziger and G. R. Schoofs, J. Phys. Chem. 88, 4439 (1984)

'B. A. Sexton, Surf. Sci. 88, 319 (1979)

D. H. S. Ying and R. J. Madix, J. Catal. 61, 48 (1980).

${ }^{8}$ N. R. Avery, Appl. Surf. Sci. 11/12, 774 (1982)

${ }^{9}$ B. A. Sexton and R. J. Madix, Surf. Sci. 105, 177 (1981)

"S. L. Miles, S. L. Bernasek, and G. L. Gland, Surf. Sci. 127, 271 (1983)

"N. R. Avery, B. H. Toby, and W. H. Weinberg, Surf. Sci. 122, L578 (1982).

''N. R. Avery, B. H. Toby, and W. H. Weinberg, J. Electron Spectrosc. 29, 233 (1983).

1'J. L. Taylor, D. E. Ibbotson, and W. H. Weinberg, J. Chem. Phys. 69, 4298 (1978).

${ }^{14}$ G. E. Thomas and W. H. Weinberg, J. Chem. Phys. 70, 954 (1979).

15 W. Tsai and W. H. Weinberg, J. Phys. Chem. 91, 5302 (1987).

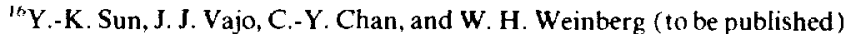

